\title{
Article \\ Cold In-Place Recycling Asphalt Mixtures: Laboratory Performance and Preliminary M-E Design Analysis
}

\author{
Dongzhao Jin ${ }^{1}\left(\mathbb{D}\right.$, Dongdong Ge ${ }^{1}\left(\mathbb{D}\right.$, Siyu Chen ${ }^{1,2}$, Tiankai Che ${ }^{1,3}$, Hongfu Liu ${ }^{1}$, Lance Malburg ${ }^{4}$ and $^{\text {, }}$ \\ Zhanping You ${ }^{1, *(1)}$
}

check for updates

Citation: Jin, D.; Ge, D.; Chen, S.; Che, T.; Liu, H.; Malburg, L.; You, Z. Cold In-Place Recycling Asphalt Mixtures: Laboratory Performance and Preliminary M-E Design Analysis. Materials 2021, 14, 2036. https://doi.org/10.3390/ma14082036

Academic Editor: Jeong Gook Jang

Received: 23 March 2021

Accepted: 16 April 2021

Published: 18 April 2021

Publisher's Note: MDPI stays neutral with regard to jurisdictional claims in published maps and institutional affiliations.

Copyright: (c) 2021 by the authors. Licensee MDPI, Basel, Switzerland. This article is an open access article distributed under the terms and conditions of the Creative Commons Attribution (CC BY) license (https:// creativecommons.org/licenses/by/ $4.0 /)$.
1 Department of Civil and Environmental Engineering, Michigan Technological University, 1400 Townsend Drive, Houghton, MI 49931-1295, USA; dongj@mtu.edu (D.J.); dge1@mtu.edu (D.G.); siychen@mtu.edu (S.C.); tche@mtu.edu (T.C.); hliu16@mtu.edu (H.L.)

2 School of Transportation, Southeast University, Nanjing 211189, China

3 School of Transportation and Logistics, Dalian University of Technology, Dalian 116024, China

4 Dickinson County Road Commission, Iron Mountain, MI 49801, USA; lance@dickinsoncrc.com

* Correspondence: zyou@mtu.edu

\begin{abstract}
Cold in-place recycling (CIR) asphalt mixtures are an attractive eco-friendly method for rehabilitating asphalt pavement. However, the on-site CIR asphalt mixture generally has a high air void because of the moisture content during construction, and the moisture susceptibility is vital for estimating the road service life. Therefore, the main purpose of this research is to characterize the effect of moisture on the high-temperature and low-temperature performance of a CIR asphalt mixture to predict CIR pavement distress based on a mechanistic-empirical (M-E) pavement design. Moisture conditioning was simulated by the moisture-induced stress tester (MIST). The moisture susceptibility performance of the CIR asphalt mixture (pre-mist and post-mist) was estimated by a dynamic modulus test and a disk-shaped compact tension (DCT) test. In addition, the standard solvent extraction test was used to obtain the reclaimed asphalt pavement (RAP) and CIR asphalt. Asphalt binder performance, including higher temperature and medium temperature performance, was evaluated by dynamic shear rheometer (DSR) equipment and low-temperature properties were estimated by the asphalt binder cracking device (ABCD). Then the predicted pavement distresses were estimated based on the pavement M-E design method. The experimental results revealed that (1) DCT and dynamic modulus tests are sensitive to moisture conditioning. The dynamic modulus decreased by $13 \%$ to $43 \%$ at various temperatures and frequencies, and the low-temperature cracking energy decreased by $20 \%$. (2) RAP asphalt incorporated with asphalt emulsion decreased the hightemperature rutting resistance but improved the low-temperature anti-cracking and the fatigue life. The M-E design results showed that the RAP incorporated with asphalt emulsion reduced the international roughness index (IRI) and AC bottom-up fatigue predictions, while increasing the total rutting and AC rutting predictions. The moisture damage in the CIR pavement layer also did not significantly affect the predicted distress with low traffic volume. In summary, the implementation of CIR technology in the project improved low-temperature cracking and fatigue performance in the asphalt pavement. Meanwhile, the moisture damage of the CIR asphalt mixture accelerated high-temperature rutting and low-temperature cracking, but it may be acceptable when used for low-volume roads.
\end{abstract}

Keywords: cold in-place recycling (CIR); disk-shaped compact tension (DCT); moisture-induced stress tester (MIST); dynamic modulus; dynamic shear rheometer (DSR); asphalt binder cracking device $(\mathrm{ABCD})$

\section{Introduction}

Asphalt recycling has increased dramatically in the past several years [1,2]. The rehabilitation of pavement also has lots of techniques, and one eco-friendly methodology is to use a CIR asphalt mixture [3,4]. CIR is a procedure whereby the overlayer of asphalt 
pavement is milled and mixed with stabilizers like emulsified asphalt [5]. Early applications of CIR focused on low-volume pavements [6]. Cost-effectiveness was the primary factor for using CIR. Bradbury et al. [7] stated it was about one-third cheaper than the original hot asphalt pavement road in Ontario. Scholz et al. [8] paved a $50 \mathrm{~mm}$ thick asphalt concrete surface with CIR and saved about $40 \%$ of the total cost. Many researchers have focused on the compaction and mixing procedure of CIR mixtures especially relating to optimum moisture content. Anderson et al. [9] discovered that in order to obtain good road performance, especially regarding strength and anti-cracking properties, optimum moisture content was the key factor that affected the on-site compaction degree and even mixing. In general, the Marshall method is always chosen to obtain the optimum moisture content [10], but the relationship between moisture and density could also help obtain it [11]. Curing time was also a vital factor affecting the CIR asphalt mixture, which is typically cured in a $60^{\circ} \mathrm{C}$ oven [12]. Woods et al. [13] implied that the criteria content of the moisture is $1.5 \%$ based on the moisture sensors at different depths in on-site CIR overlays.

Quantitative researchers have concentrated on the performance characterization test of the CIR asphalt mixture. Wu et al. [14] conducted asphalt concrete APA fatigue tests by using a more traditional theoretical analysis. Marshall stability has traditionally been the main criterion used to select design binder content for bituminous-stabilized CIR mixtures. Yan et al. [15] stated that APA test was conducted by many researchers to estimate antirutting performance, and he suggested that Marshall stability should be larger than at 6 $\mathrm{kN}$ at $40{ }^{\circ} \mathrm{C}$. Du and Cross [16] used three types of CIR mixture (1.5\% asphalt emulsion, $1.5 \%$ asphalt emulsion with hydrated lime, $1.5 \%$ asphalt emulsion with quick lime) to test rutting performance using APA tests, and the rut depth ranged from 0.37 to $0.67 \mathrm{~cm}$. Indirect Tensile Strength has been used by many people to study CIR asphalt mixture performance. Yan et al. [15] suggested that the peak load at $15^{\circ} \mathrm{C}$ should be larger than $0.5 \mathrm{MPa}$. Kavussi and Modarres [17] conducted an IDT test of CIR mixtures and figured out that the coefficient of variation is no larger than 0.1 in most cases; Thomas et al. [18] tested two types of CIR mixture by an IDT test and by creep compliance and strength to characterize low temperature cracking performance. Based on the above literature review, the performance was one of the vital factors in CIR asphalt mixtures. In this study, all loose materials used were obtained from Dickinson County Road 581, located on the Upper Peninsula of Michigan, where the lowest temperature was below $0{ }^{\circ} \mathrm{C}$ for almost half a year, indicating that low-temperature performance is important for road service. Meanwhile, CIR performance at high temperatures is important in summertime [19,20]. A CIR asphalt mixture commonly has higher air voids, which may cause moisture damage. Therefore, it is necessary to investigate the CIR asphalt mixture moisture resistance.

The main purpose of this research is to characterize the effect of moisture on the high-temperature and low-temperature performance of CIR asphalt mixture and to predict pavement distress and deterioration based on a mechanistic-empirical pavement design. The low-temperature cracking performance of the CIR asphalt mixture was estimated by the DCT test. The dynamic modulus was conducted to evaluate the stress and strain response of the CIR asphalt mixture at various temperatures and frequencies. In addition, the Moisture-Induced Stress Tester (MIST) was used to simulate the pore pressure generated in a wet pavement under moving traffic loading. The standard solvent extraction test was used to obtain the reclaimed asphalt pavement (RAP) and CIR asphalt. The hightemperature and fatigue performances were characterized by a dynamic shear rheometer (DSR) equipment, while the low-temperature properties were investigated by the asphalt binder cracking device (ABCD). Then the predicted pavement distresses were estimated based on the M-E inputs.

\section{Materials and Methods}

\subsection{Materials and Mixture Design}

All the loose mixtures are obtained from Dickinson County Road 581 in Michigan, USA. The mix design was conducted by the Superpave mix design. The RAP materials 
obtained from the milled surface asphalt pavement layer were utilized with $2.5 \%$ emulsion content (64.8\% residue content) and an additional $2 \%$ water content based on the mix design results shown in Table 1. The average bulk specific gravity is 2.129 . The gradation used in this study is shown in Figure 1. The Superpave gyratory compactor (SGC, manufacturer: PINE test equipment, Grove City, PA, USA) gyration time is 30 for CIR mixture in nearly all US states [21], so the gyration time was 30 and the mass was cured at $60{ }^{\circ} \mathrm{C}$ for $48 \mathrm{~h}$ until it was constant. The average air voids were $13 \%$. The SGC compaction procedure was followed the AASHTO PP 60-09 specification [22].

Table 1. Mix design for CIR asphalt mixture.

\begin{tabular}{ccccc}
\hline Test Parameters & & Test Results & Specification Requirement \\
\hline Emulsion Content & $2.0 \%$ & $2.5 \%$ & $3.0 \%$ & - \\
\hline Optimum Water for Mixing & $2.0 \%$ & $2.0 \%$ & $2.0 \%$ & - \\
\hline Bulk Specific Gravity & 2.110 & 2.125 & 2.132 & - \\
\hline Maximum Theoretical Specific Gravity & 2.443 & 2.440 & 2.436 & - \\
\hline Air Voids & $13.6 \%$ & $12.9 \%$ & $12.5 \%$ & $5.56 \mathrm{kN} \mathrm{min}$ \\
\hline Conditioned Marshal Stability (kN) & 7.80 & 7.16 & 7.28 & - \\
\hline Retained Stability & $74 \%$ & $76 \%$ & $70 \%$ & $70 \% \mathrm{~min}$ \\
\hline Raveling Test & $1.61 \%$ & $0.30 \%$ & $0.19 \%$ & $2 \% \mathrm{Max}$
\end{tabular}

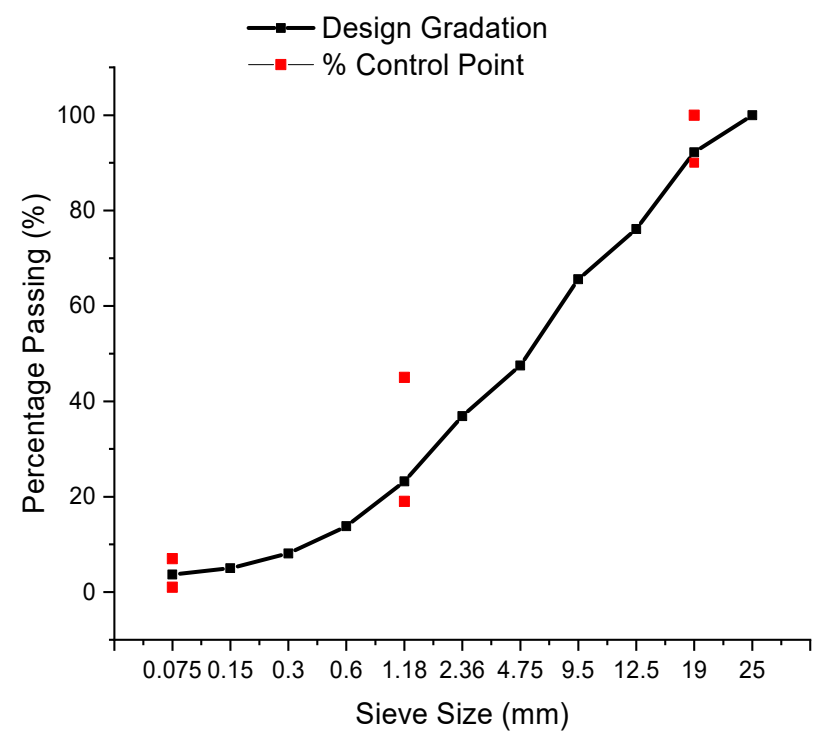

Figure 1. The gradation used in this study.

\subsection{Experimental Program}

This section concerns the laboratory mixture experiments, which included the moisture conditioning test (MIST), the dynamic modulus test, and the low-temperature DCT test. The laboratory binder experiments, including the standard solvent extraction test, were used to obtain the reclaimed asphalt pavement (RAP) and CIR binder. The dynamic shear rheometer (DSR, manufacturer: Anton Paar, North Ryde, Australia), the asphalt binder cracking device $(A B C D)$ test, and then the prediction pavement distress were estimated by the M-E design. The technical flowchart is shown in Figure 2. 


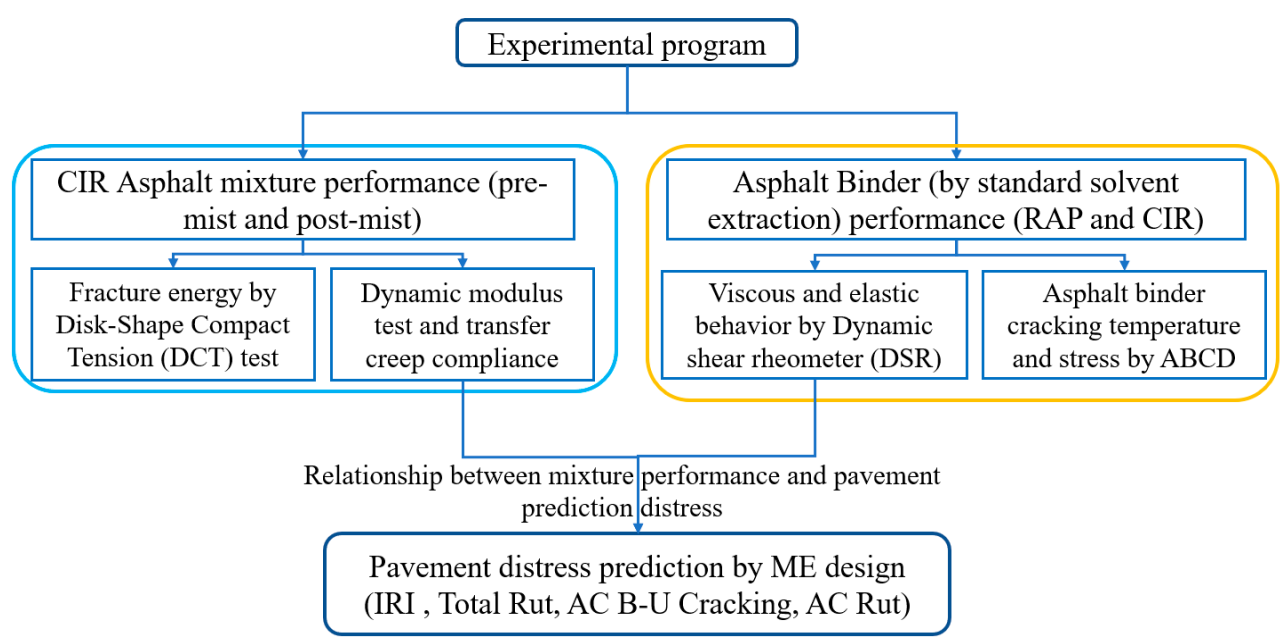

Figure 2. The technical flowchart of this study.

\subsection{Asphalt Mixture Test Program \\ 2.3.1. Moisture Conditioning via MIST}

A CIR asphalt mixture generally shows a high air void, and it causes the asphalt mixture to be more sensitive to moisture damage [23]. Therefore, there is a need to investigate the moisture conditioning performance of the CIR asphalt mixture. The Moisture Induced Stress Tester (MIST, manufacturer: InstroTek, Grand Rapids, MI, USA) is designed to be a quick and logical method for testing the moisture damage susceptibility of asphalt mixture, which is specified in ASTM D7870 [24]. The samples for the dynamic modulus and disk-shaped compact tension tests were conditioned by MIST. It should be noted that the moisture conditioning was set for 500 cycles at $40^{\circ} \mathrm{C}$ for the CIR asphalt mixture. Specifically, the CIR asphalt mixture without moisture conditioning was labeled as "pre-mist", while the CIR asphalt mixture under moisture conditioning was labeled as "post-mist".

\subsubsection{Low-Temperature Cracking Test}

Dickinson County Road 581 is located on the Upper Peninsula of Michigan where the lowest temperature was less than $0{ }^{\circ} \mathrm{C}$ for almost half a year, which means that lowtemperature performance is vital for road service. The DCT test is used to evaluate the low-temperature cracking resistance of the asphalt mixture and is based on ASTM D7313 [25], "Standard Test Method for Determining Fracture Energy of Asphalt Mixtures Using the Disk-Shaped Compact Tension Geometry". The test is generally used to obtain the fracture energy, peak load, and maximum crack mouth-opening displacement (CMOD). The DCT test temperature for the CIR asphalt mixture was $-12{ }^{\circ} \mathrm{C}$ based on the PG level. The test was run with a constant CMOD control mode, and the CMOD rate was $1 \mathrm{~mm} / \mathrm{min}$. The CMOD after the peak load reflected the propagation of cracking inside the sample during the DCT test. The specimen's geometry for a DCT test is a cylinder with a diameter of $150 \mathrm{~mm}$ and height of $45 \mathrm{~mm}$. The details of the DCT test are shown in Figure 3. It should be mentioned that at least three parallel samples were used for each test. 


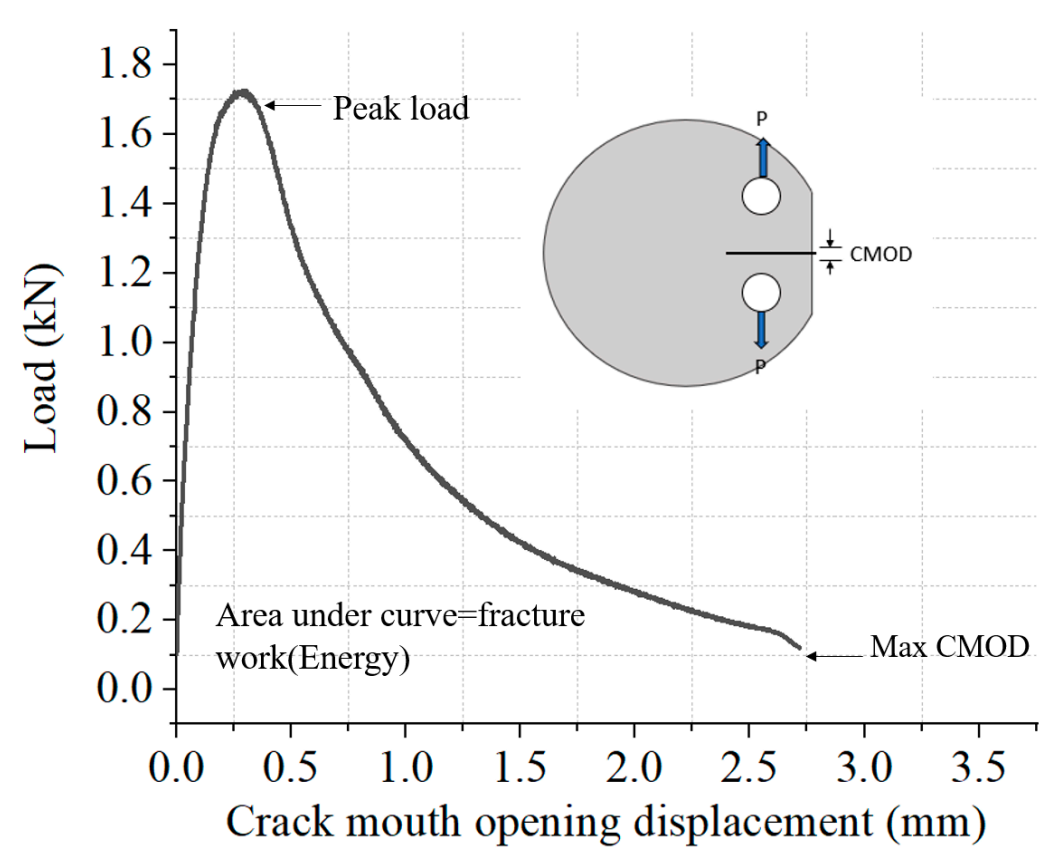

Figure 3. Demonstration of the DCT test procedure.

\subsubsection{Dynamic Modulus Test}

The dynamic modulus could be used directly to reflect the stress and strain response by specific load $[26,27]$. The dynamic modulus $\left(\mathrm{E}^{*}\right)$ test is conducted at temperatures of $-10{ }^{\circ} \mathrm{C}, 10^{\circ} \mathrm{C}, 21^{\circ} \mathrm{C}$, and $37^{\circ} \mathrm{C}$, and at loading frequencies of $0.1 \mathrm{~Hz}, 0.5 \mathrm{~Hz}, 1 \mathrm{~Hz}, 5 \mathrm{~Hz}$, $10 \mathrm{~Hz}$, and $25 \mathrm{~Hz}$ at each temperature. The UTM-100 equipment was used for this test, and it is specified in AASHTO T342. The temperature chamber of the UTM-100 machine can control the temperature from -15 to $60^{\circ} \mathrm{C}$. The diameter and height of the test specimens were $100 \mathrm{~mm}$ and $150 \mathrm{~mm}$, respectively. The dynamic modulus $\left(\left|\mathrm{E}^{*}\right|\right)$ reflected the elastic performance of the asphalt mixture, and the phase angle $(\delta)$ expressed the gap between the stress and the strain. The rutting parameter $\left(\left|\mathrm{E}^{*}\right| / \sin \delta\right)$ and fatigue parameter $\left(\left|\mathrm{E}^{*}\right| \cdot \sin \right.$ $\delta)$ could reflect the rutting and fatigue properties of the two types of asphalt mixtures. The master curve of the dynamic modulus was plotted for both the dynamic modulus of asphalt mixture and asphalt binder. It could be used to reveal the high-temperature performance and low-temperature performance. The details of the dynamic modulus master curve are shown in Figure 4. The specimen's geometry for the dynamic modulus test is a cylinder with a diameter of $100 \mathrm{~mm}$ and height of $150 \mathrm{~mm}$. It should be mentioned that at least three parallel samples were used for each test.

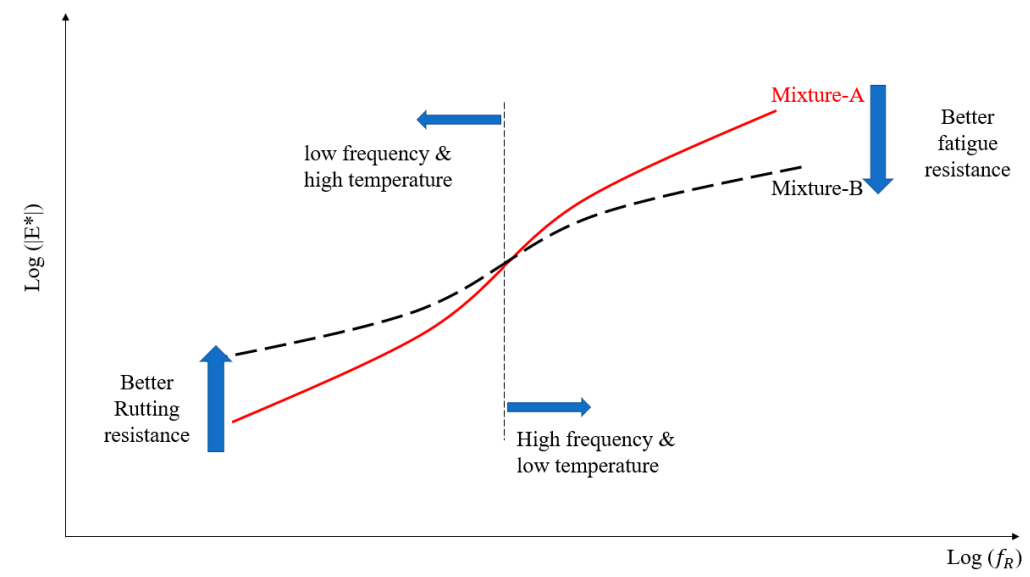

Figure 4. Demonstration of the dynamic modulus master curve. 


\subsubsection{Creep Compliance}

Creep compliance at low temperature could be used to reflect the thermal cracking at the low temperature of the asphalt mixture. It is based on AASHTO T322 (2011) [28] "Determining the Creep Compliance and Strength of Hot Mix Asphalt (HMA) Using the Indirect Tensile Test Device". Creep compliance would be estimated from the $\left|E^{*}\right|$ master curve using the procedure developed in 1999 by S.W. Park and R.A. Shapery [29]. The master curve of dynamic modulus $\left|\mathrm{E}^{*}\right|$ could be used to characterize the linear viscoelastic behavior of asphalt mixtures and conversion between the time and frequency domains.

\subsection{Asphalt Binder Test Program}

\subsubsection{Standard Solvent Extraction}

The properties of CIR asphalt also show significant variants compared with RAP asphalt from the milled pavement. Therefore, there is a need to characterize the extraction of asphalt binder properties. The automatic asphalt analyzer (manufacturer: CONTROLS Inc., Chicago, IL, USA) was used for the washing of the CIR loose mixture (around $3.5 \mathrm{~kg}$ ) with trichloroethylene (TCE) solvent, ultrasonic motion, simultaneous heating, and rotation of the drum lined with screening mesh, which is specified in ASTM D8159-19 [30]. The solvent mix incorporated with asphalt binder was moved to the rotary evaporator device to remove the solvents from the asphalt binder by evaporation extracts. Asphalt binder washed out from the mixture with the Automatic Asphalt Analyzer could be separated from the asphalt. In short, the extracted asphalt binder from the RAP loose mixture could be written as RAP, and the extracted asphalt from the CIR loose mixture could be written as CIR.

\subsubsection{Dynamic Shear Rheometer (DSR)}

The viscous and elastic property of asphalt at medium and high temperatures was characterized by dynamic shear rheometer equipment, which characterized high-temperature and fatigue performance. The high-temperature rheological properties were be conducted at a temperature of $34,40,46,52,58,64,70,76$, and $82^{\circ} \mathrm{C}$ at loading frequencies of 0.628 , $6.28,9.99,18.8,31.4$, and $62.8 \mathrm{rad} / \mathrm{s}$ for each temperature. The intermediate temperature was conducted at a temperature of $13,16,19,22$, and $25^{\circ} \mathrm{C}$ at loading frequencies of 0.628 , $6.28,9.99,18.8,31.4,62.8 \mathrm{rad} / \mathrm{s}$ for each temperature. The test procedure was based on the AASHTO 315 specification. At least three parallel samples were used for each test.

\subsubsection{Asphalt Binder Cracking Device (ABCD)}

The $A B C D$ is a new empirical test for evaluating the low-temperature cracking potential of asphalt binder. The cracking temperature and cracking stress can be obtained from the test, which is specified in AASHTO TP 92(2014) [31]. Strain and temperature are recorded until the cracking starts. The $\mathrm{ABCD}$ system consists of an air-cooled environmental chamber that can automatically cool asphalt specimens at a constant rate $\left(20^{\circ} \mathrm{C} / \mathrm{h}\right)$ from $25^{\circ} \mathrm{C}$ to $-60^{\circ} \mathrm{C}$. The $\mathrm{ABCD}$ invar rings are equipped with an electrical-strain reading gauge, temperature control sensor, and silicone rubber specimen molds. Typical ABCD setup and test results are shown in Figure 5. At least three parallel samples were used for each test. 


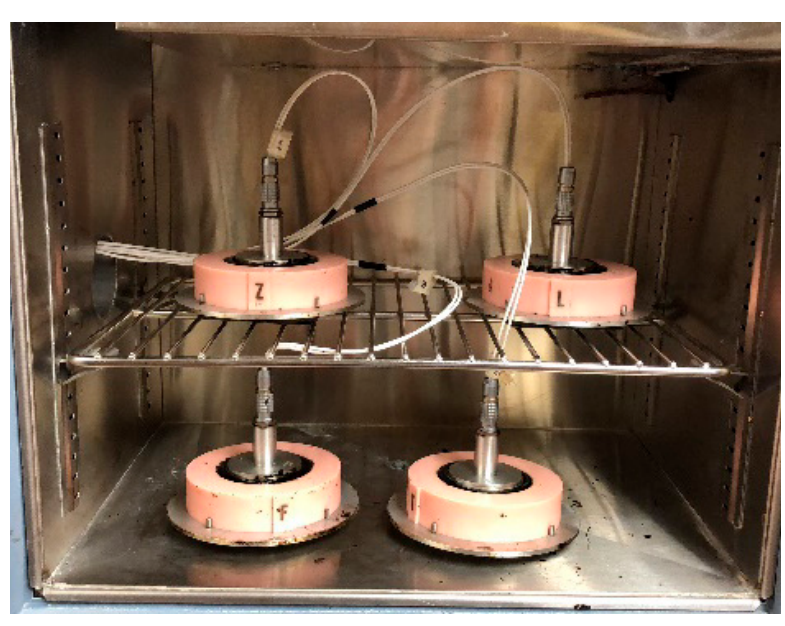

(a) Asphalt Binder Cracking Device (ABCD) test apparatus

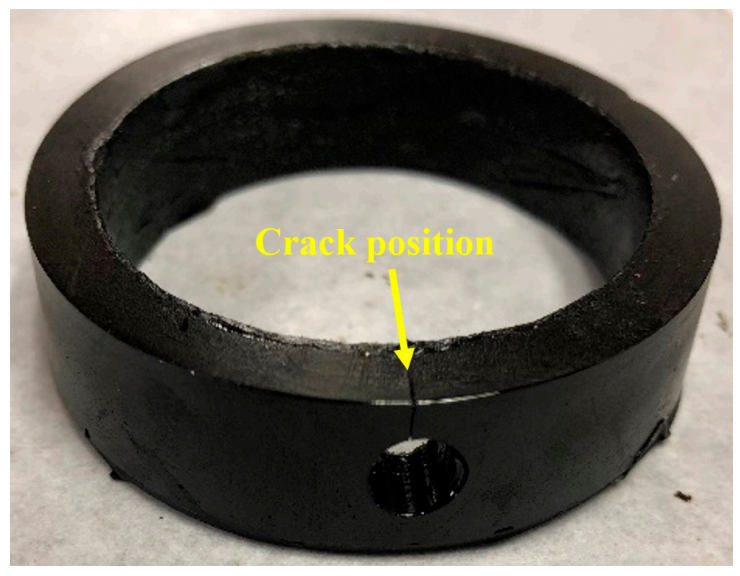

(c) Sample with crack after the test

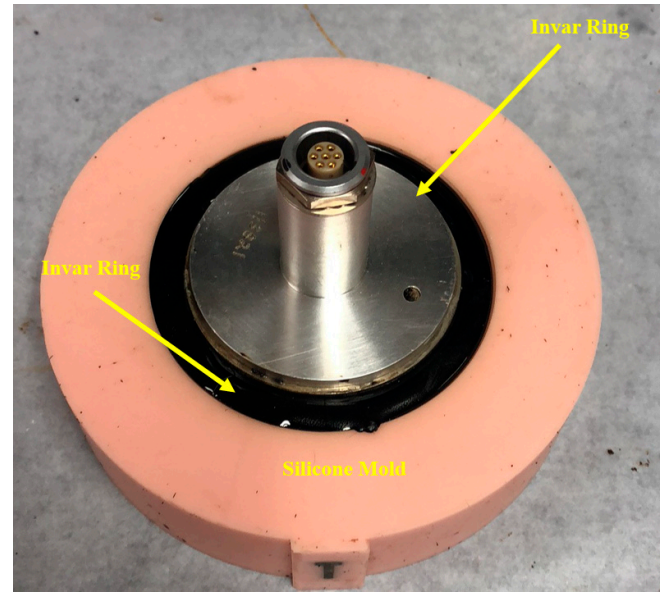

(b) Sample in the mold

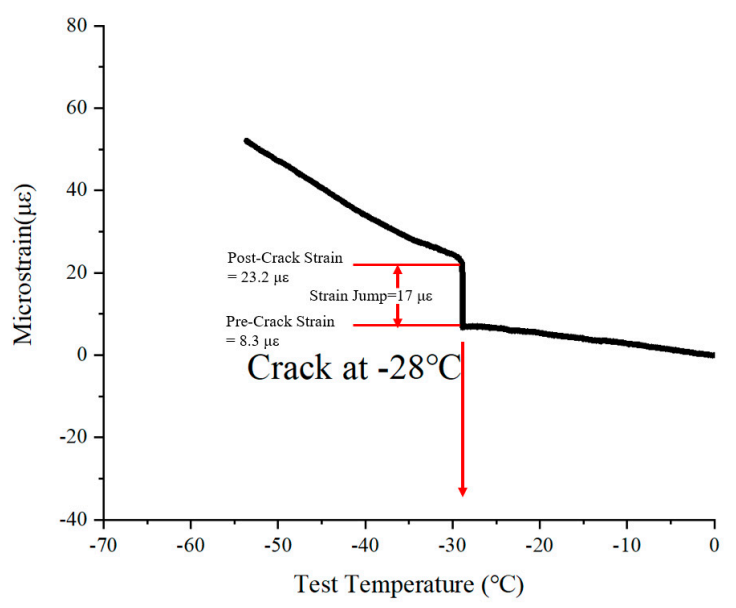

(d) Typical ABCD results

Figure 5. The Asphalt Binder Cracking Device (ABCD) test apparatus and procedure: (a) Asphalt Binder Cracking Device $(\mathrm{ABCD})$ test apparatus; (b) Sample in the mold; (c) Sample with crack after the test; (d) Typical ABCD results.

\subsection{Pavement Distress Prediction by Pavemeent M-E Design Analysis}

The M-E Design [29] was used to evaluate the difference in the asphalt binder performance between the RAP and CIR asphalt, especially for the permanent deformation and fatigue cracking. The dynamic modulus pre-mist and post-mist conditions were also used to predict the effect of moisture damage in the CIR asphalt layer on pavement distress. The test parameters were the following: vehicle growth rate was $0.5 \%$, the design life was 20 years, design speed was $90 \mathrm{~km} / \mathrm{h}$, the annual average daily traffic (AADT) in 2019 was 778 , design function of the traffic volume was compound, and the number of lanes was 2. The traffic value, including single axle, tandem axle, tridem axle, quad axle distribution, was set according to the Buch research report [30]. The climate was the near place according to the M-E used guide recommendation. The specific calibration factor was according to the Michigan DOT User Guide for Mechanistic-empirical Pavement Design 2020, and the pavement structure and thickness used in this road is shown in Figure 6. 


\begin{tabular}{|c|c|}
\hline Structure & Materials type and thickness \\
\hline Top course & $3.8 \mathrm{~cm}$ HMA 5E1, PG 58-34 \\
\hline Levelling course & $12.7 \mathrm{~cm} \mathrm{CIR}$ \\
\hline Base course & $10 \mathrm{~cm}$ gravel base \\
\hline Sand subbase & $90 \mathrm{~cm}$ gravel subbase \\
\hline subgrade & Sandy clay subgrade \\
\hline
\end{tabular}

Figure 6. Demonstration of the structure and materials used in this study.

\section{Results and Discussions}

\subsection{Dynamic Modulus Test Results}

Figure 7 shows the dynamic modulus master curve at a reference temperature of $21{ }^{\circ} \mathrm{C}$ for the pre-mist and post-mist CIR asphalt mixture. It was determined that the stiffness of all mixtures would decrease after moisture conditioning. As we all know, a lower reduced frequency represents slow traffic speeds or high pavement temperature, and a higher reduced frequency indicates high traffic speeds or low pavement temperature. Both the lower and high reduced frequencies showed that a reduction in stiffness in post-mist CIR asphalt mixture compared with the pre-mist CIR asphalt mixture.

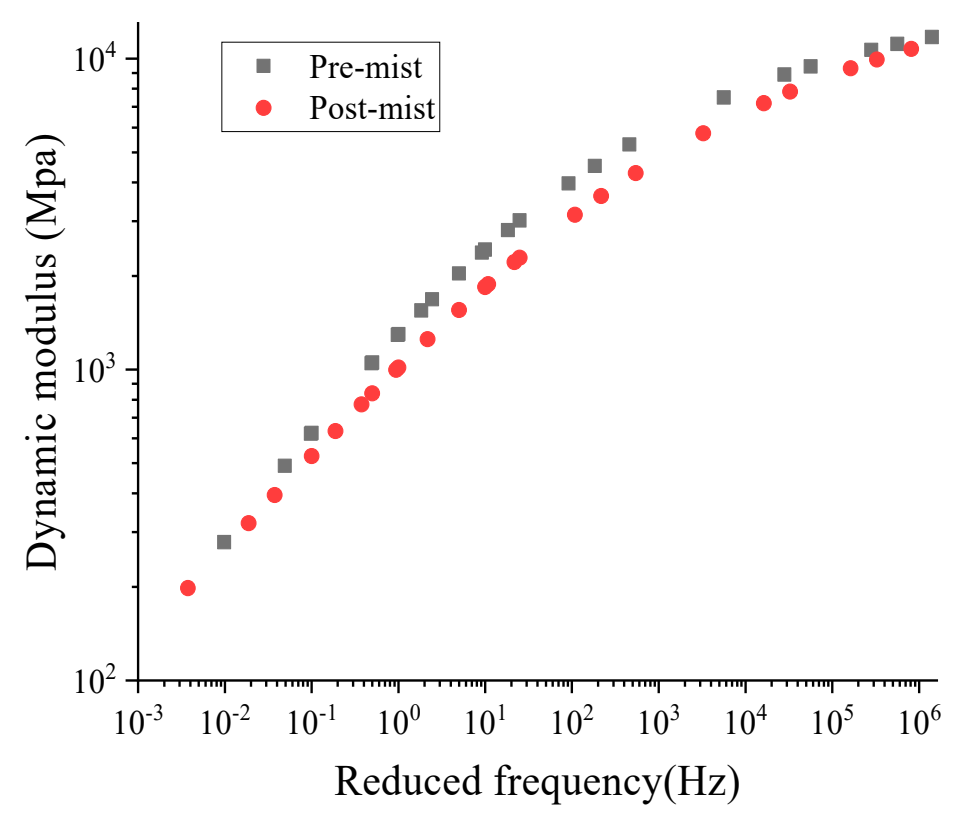

Figure 7. Master curve of dynamic modulus at $21^{\circ} \mathrm{C}$ of pre-mist and post-mist CIR asphalt mixture.

The phase-angle master curve at the reference temperature of $21^{\circ} \mathrm{C}$ between the pre-mist and post-mist CIR is shown in Figure 8. It was apparent that the phase angle increased after MIST conditioning. At lower frequencies, the phase angle increased as little as 0.2 degrees, while it could be 1 degree at high frequencies. The reason is that after MIST conditioning, the asphalt mixture displayed more viscous action under loading. The results from the dynamic modulus test indicated that after the moisture damage, the asphalt mixture experienced a decrease in modulus and an improvement in phase angle, which meant that the asphalt mixture was softer after the moisture damage. 


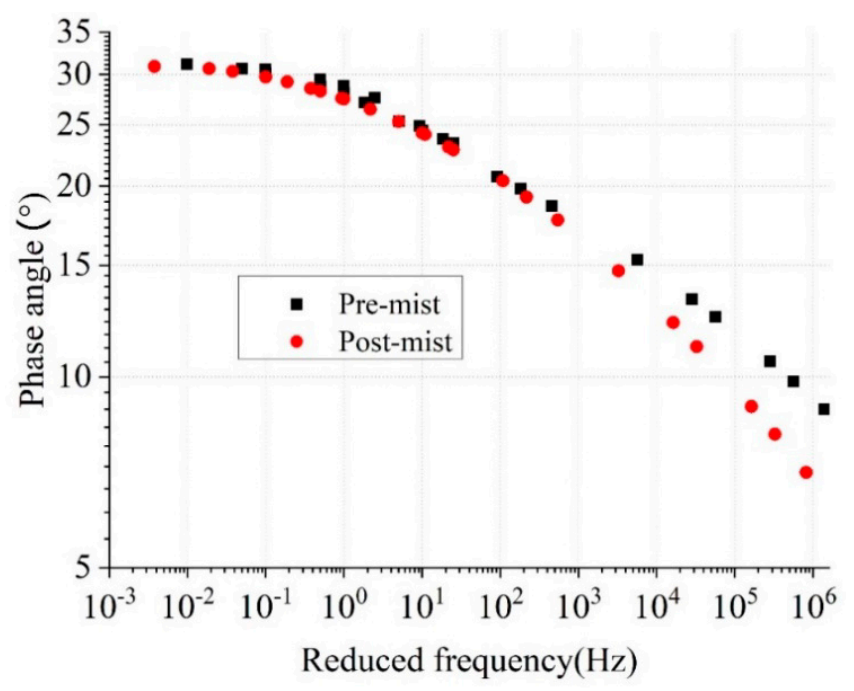

Figure 8. Master curve of phase angle at $21^{\circ} \mathrm{C}$ of pre-mist and post-mist CIR asphalt mixture.

The rutting index of the pre-mist and post-mist CIR mixtures at the loading frequency of $10 \mathrm{~Hz}$ is displayed in Figure 9. The rutting parameter $\left(\left|\mathrm{E}^{*}\right| / \sin \delta\right)$ quantifies the rutting property of the asphalt mixture. The MIST process reduced the rutting parameter of the mixture. For example, the rutting parameter of the asphalt mixture decreased by $13 \%$ at $-10{ }^{\circ} \mathrm{C}$ and by $41 \%$ at $37^{\circ} \mathrm{C}$. This reduction effect was significant at high temperatures, which was very important because at high temperatures rutting was easier to accumulate on the pavement. The stiffness of the asphalt mixture decreased after fiber modification, thus weakening the rutting resistance of the asphalt mixture. It should be mentioned that the high value of error bar at $-10^{\circ} \mathrm{C}$ may be caused by moisture frozen in the mixture.

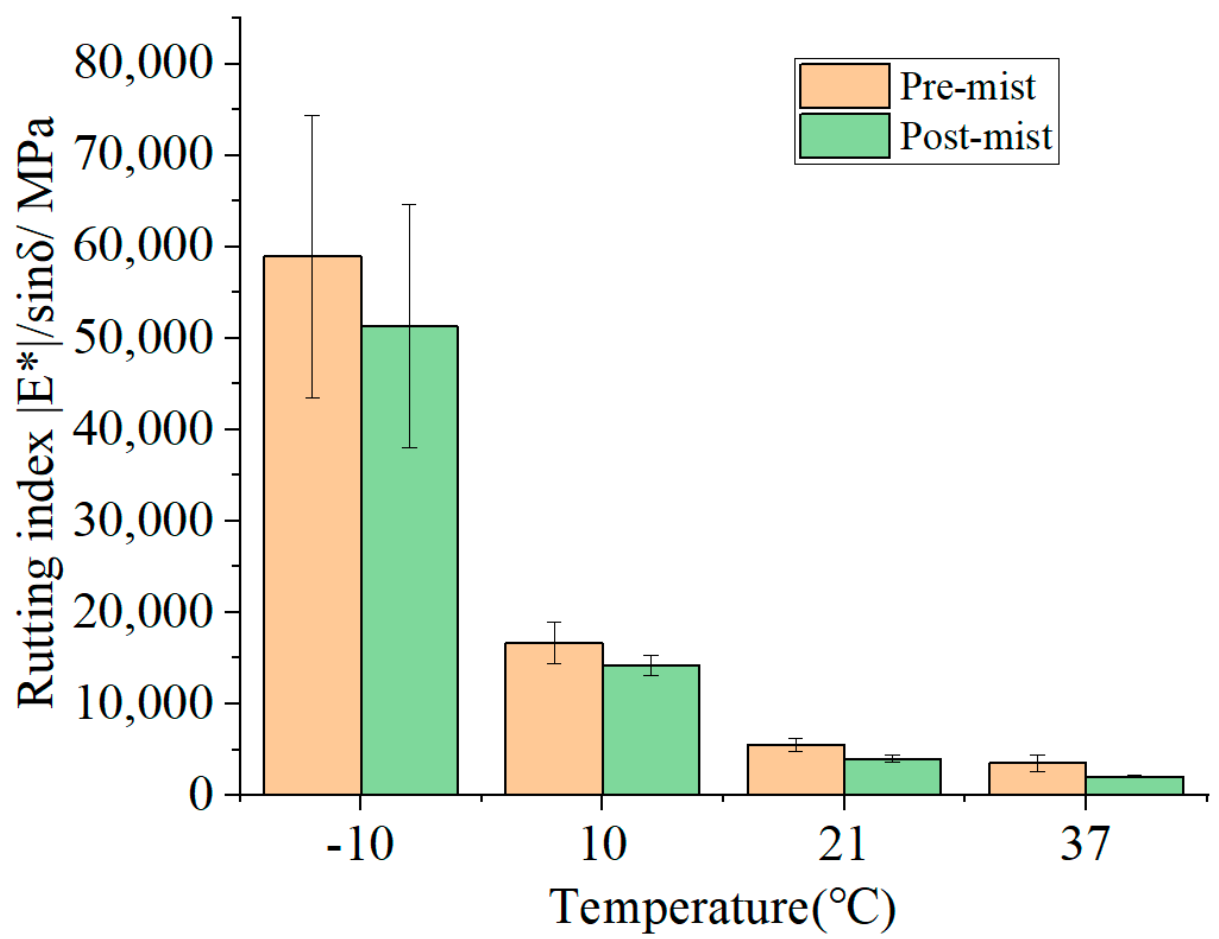

Figure 9. Rutting index at $10 \mathrm{~Hz}$ of pre-mist and post-mist CIR asphalt mixture.

The moisture susceptibility of the pre-mist and post-mist CIR mixture was evaluated by the dynamic modulus ratio. For CIR, this was defined by the ratio of the dynamic modulus of pre-mist CIR mixture to that of the post-mist CIR mixture. The results of the 
various mixtures at different temperatures and frequencies are presented in Figure 10. The lower dynamic modulus ratio values were observed with a decrease in loading frequency and increase in temperature. The reduction in stiffness was more pronounced at lower frequencies, and after conditioning the material experienced a decrease in stiffness at all temperatures. These results indicated that asphalt mixtures were more affected by humidity regulation at lower traffic speeds and higher temperatures.

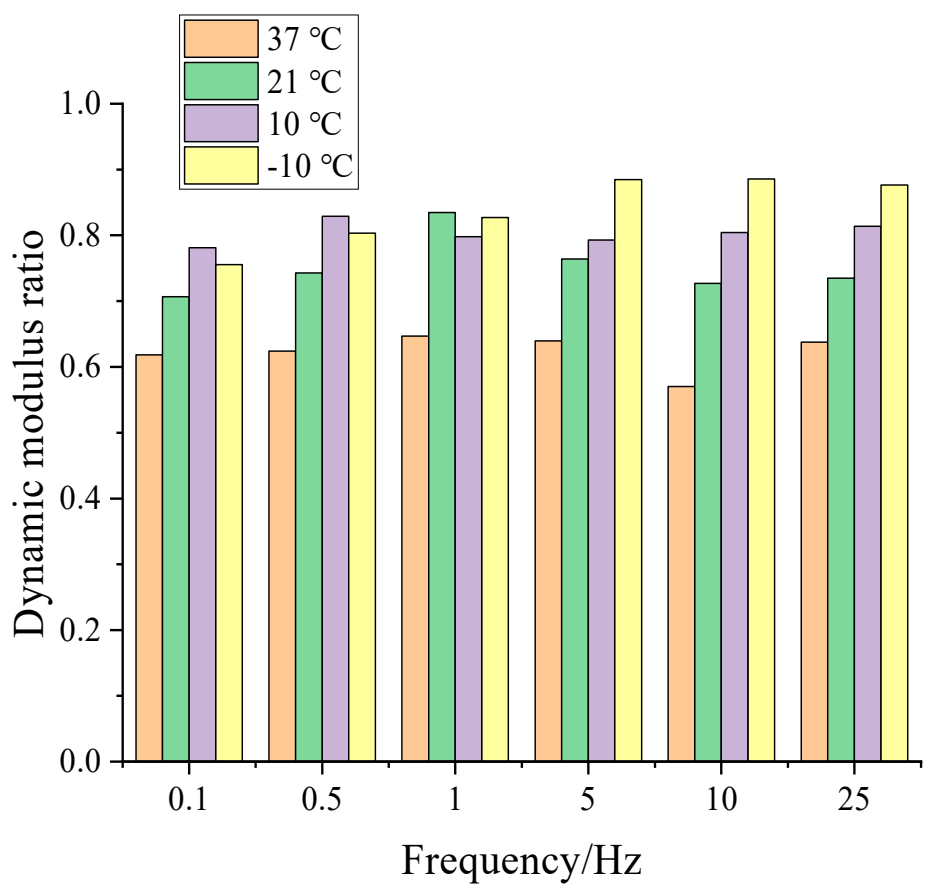

Figure 10. Dynamic modulus ratio of pre-mist and post-mist CIR mixture at $10 \mathrm{~Hz}$.

\subsection{Creep Compliance}

Creep compliance at low temperature was used to determine the cracking resistance for the asphalt mixture $[32,33]$. Creep compliance revealed low-temperature behavior and predicted the thermally induced cracking in asphalt pavement at low temperature in the U.S. [34]. The results for the pre-mist and post-mist CIR mixtures, are shown in Figure 11. The temperature increases caused the creep compliance to increase as did the duration time increase. It is clear that the post-mist CIR showed higher creep compliance under various temperatures and times. For example, it increased by $55 \%$ from $4.396 \times 10^{-6}$ to $6.85 \times 10^{-6}$. This meant that the stiffness of the post-mist CIR mixture decreased and the low temperature cracking resistance decreased compared with the pre-mist CIR mixture.

\subsection{DCT Test Results}

Low-temperature cracking resistance was evaluated by the DCT test, which investigated the implications of the CIR mixture on low-temperature cracking. The fracture energy directly expressed the cracking performance of the asphalt mixture, and the mixture with the higher fracture energy had a better low-temperature cracking property. The fracture energy of the pre-mist and post-mist CIR mixture is displayed in Figure 12b. Pre-mist CIR mixture showed better low temperature cracking resistance compared with the post-mist CIR mixture. The recommended low-temperature crack resistance threshold determined by MnDOT is $400 \mathrm{~J} / \mathrm{m}^{2}$ [33]. The peak load of the DCT test defines the force needed to initiate the cracking in the asphalt mixture at low temperatures. The peak load represents the cracking propagation possibility of the asphalt mixture; an asphalt mixture with a higher peak load was harder to crack. The peak load of the two asphalt mixtures under different temperatures is shown in Figure 12c. The maximum CMOD represents the deformation that occurs in the asphalt mixture during the DCT test. The asphalt mixture with a higher 
maximum CMOD had better deformation ability under low temperatures. The maximum CMOD of the pre-mist and post-mist CIR mixture is displayed in Figure 12d. The pre-mist CIR mixture showed better low temperature cracking resistance compared with the postmist CIR mixture. The results of the DCT test were consistent with the results obtained from creep compliance.

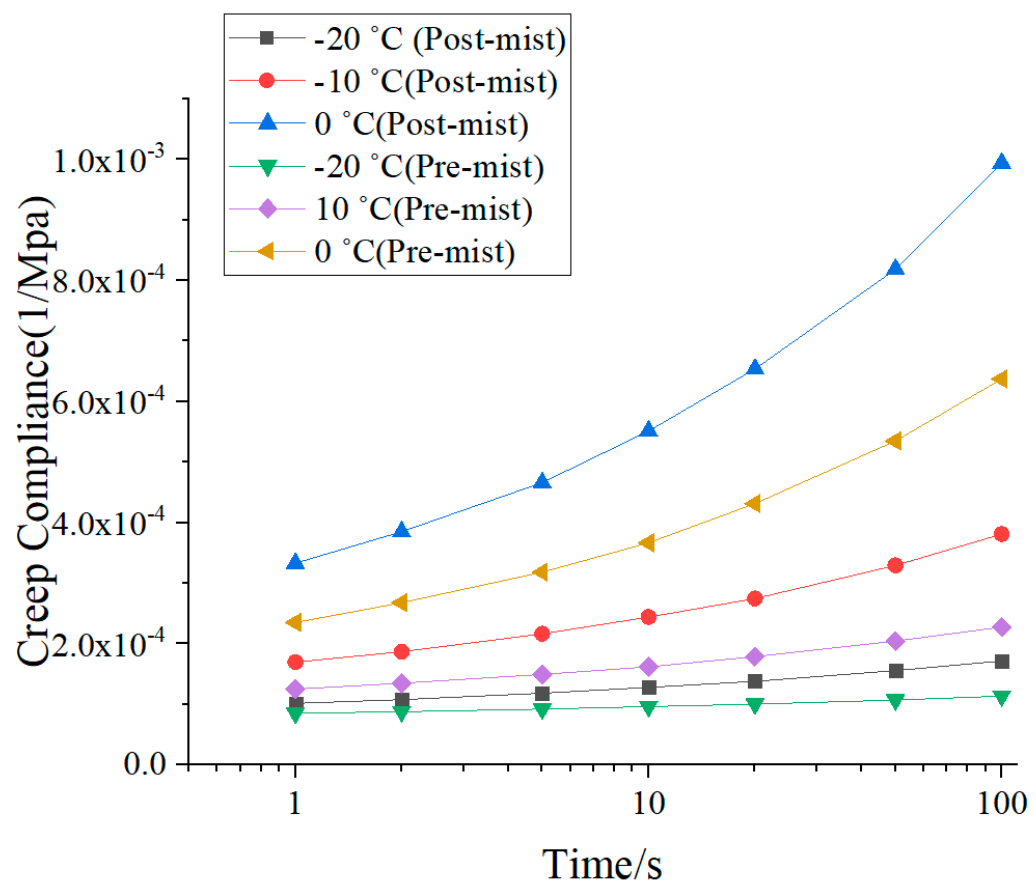

Figure 11. Creep compliance results of pre-mist and post-mist CIR asphalt mixture.

\subsection{DSR results}

The complex modulus of RAP asphalt and CIR asphalt under six frequencies at $58{ }^{\circ} \mathrm{C}$ were displayed in Figure 13a. RAP and CIR asphalt were extracted from the loose materials. Asphalt extracted from the loose materials did not need any aging to simulate the short-term and long-term performance. It was determined that the presence of emulsion asphalt decreased the complex modulus because it made the asphalt softer compared with RAP. Simultaneously, the complex modulus of CIR and RAP asphalt increased with as the frequency increased. For example, the complex modulus of the RAP asphalt binder was $20.95 \mathrm{kPa}$ at $1.00 \mathrm{~Hz}$, and it increased $44.97 \%$ and $464.21 \%$ to $1.59 \mathrm{~Hz}$ and $10.00 \mathrm{~Hz}$, respectively. The reason for this is that asphalt shows higher elastic components and properties with the increased frequency. In contrast, a lower frequency, which represents a longer loading time, generally causes the asphalt to display more viscous properties. This evidence could be used to reveal the reason that rutting distress appears more easily on longitudinal-slope asphalt pavement over long distance. An automobile would generally be driven at low speed over a long time, thus producing low-frequency-related properties. 


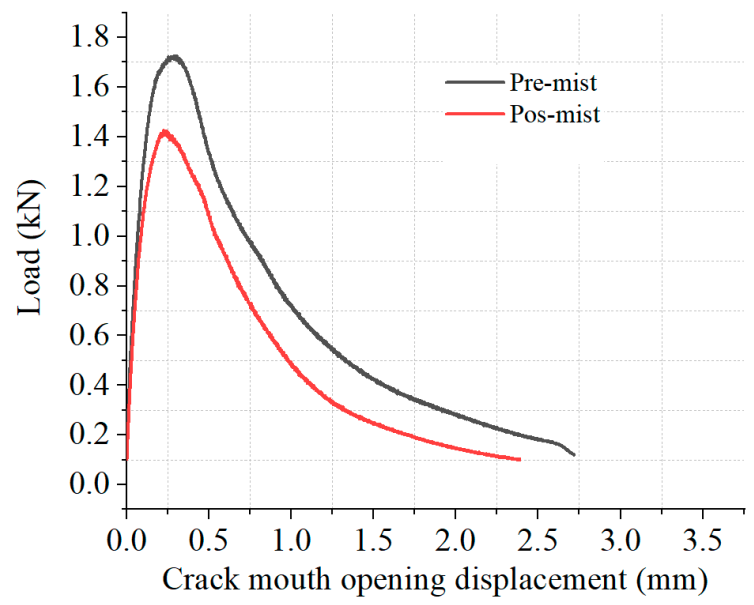

(a) CMOD vs. Load between pre-mist and post-mist

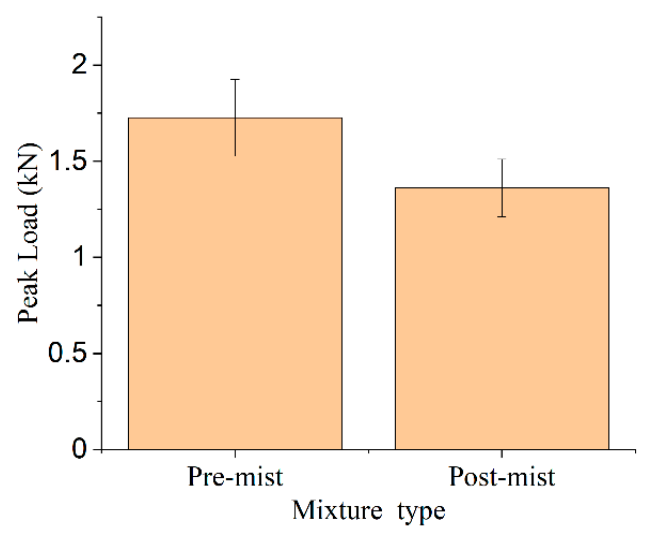

(c) peak load difference between pre-mist and post-mist

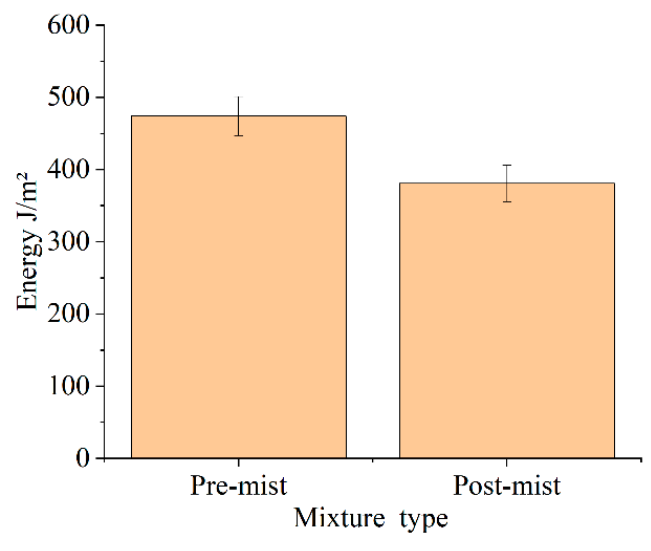

(b) Energy difference between pre-mist and post-mist

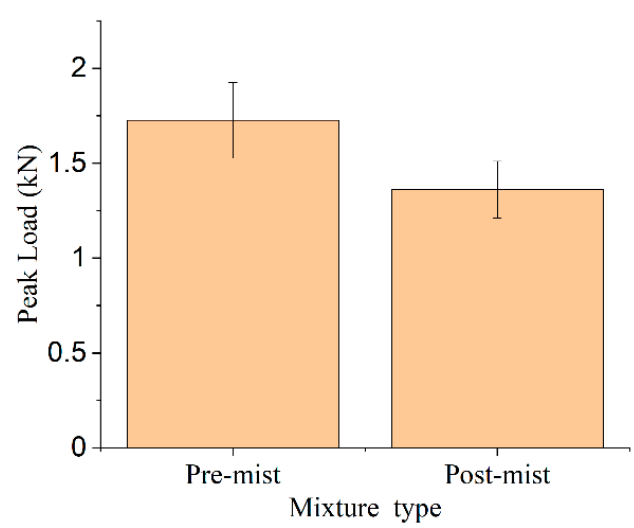

(d) Maximum CMOD difference between pre-mist and post-mist

Figure 12. Low-temperature cracking resistance results of pre-mist and post-mist CIR asphalt mixture: (a) CMOD vs. Load between pre-mist and post-mist; (b) Energy difference between pre-mist and post-mist; (c) peak-load difference between pre-mist and post-mist; (d) Maximum CMOD difference between pre-mist and post-mist.

Figure $13 \mathrm{~b}$ illustrates the master curves of phase angles at $58^{\circ} \mathrm{C}$. As the phase angle decreased, the viscous component of asphalt decreased, and the elastic component increased. The addition of emulsified asphalt increased the phase angle of the asphalt. The master curves of the rutting factor for RAP asphalt and CIR asphalt at $58^{\circ} \mathrm{C}$ are shown in Figure 13c. It is worth mentioning that low temperature corresponded to the highly reduced frequency. It was revealed that the rutting index increased with increasingly reduced frequency. Meanwhile, the asphalt had more elastic components and a higher resistance to deformation under low-temperature conditions. This was consistent with the fact that a lower temperature indicated a higher rutting coefficient and better resistance to deformation. For example, adding emulsion to the RAP asphalt binder caused the rutting factor value to decrease throughout the reduced frequency, which indicated that the stiffness of the asphalt binder had been reduced compared to that of the RAP asphalt. The master curves of fatigue factor for the two types of asphalt at the reference temperature of $19^{\circ} \mathrm{C}$ are presented in Figure 13d. In order to resist fatigue cracking, an asphalt binder should be elastic (able to dissipate energy by rebounding, not cracking) but not too stiff 
(excessively stiff substances will crack rather than deform and rebound). Therefore, the complex shear modulus viscous portion $\left|G^{*}\right| \times \sin \delta$ should be minimal. It is clear that the addition of emulsified asphalt in the RAP asphalt decreased the $\left|G^{*}\right| \times \sin \delta$ value of the asphalt, which may improve the resistance of fatigue cracking properties.

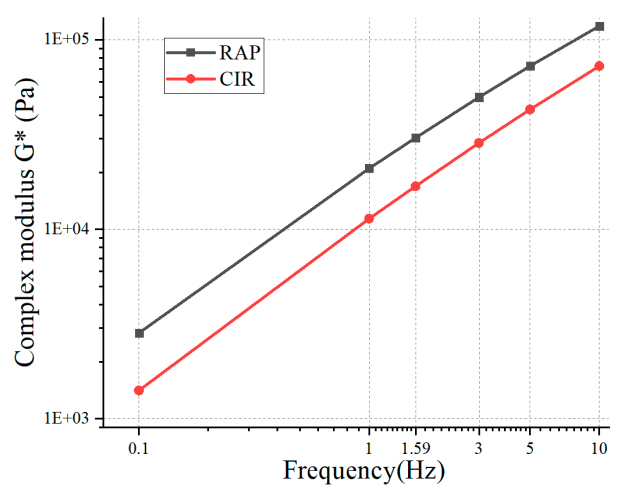

(a) The complex modulus of asphalt binder at $58^{\circ} \mathrm{C}$

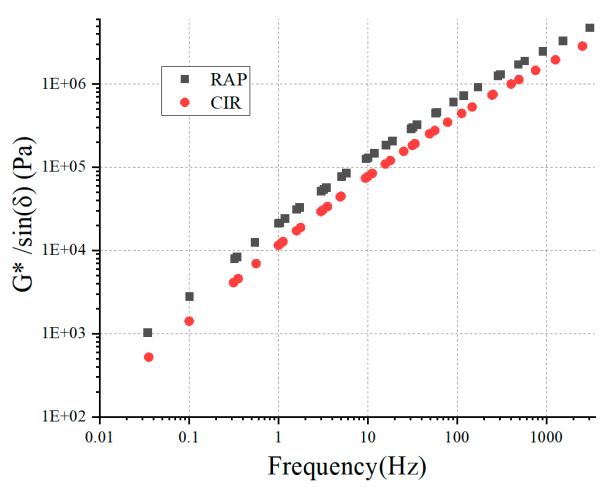

(c) Master curve of rutting factor at $58^{\circ} \mathrm{C}$

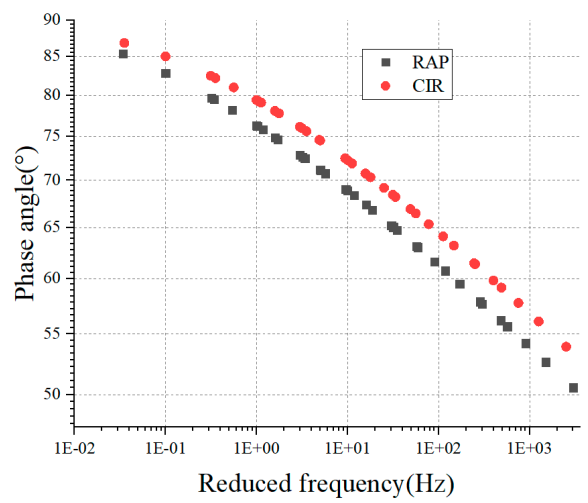

(b) Master curve of phase angle at $58^{\circ} \mathrm{C}$

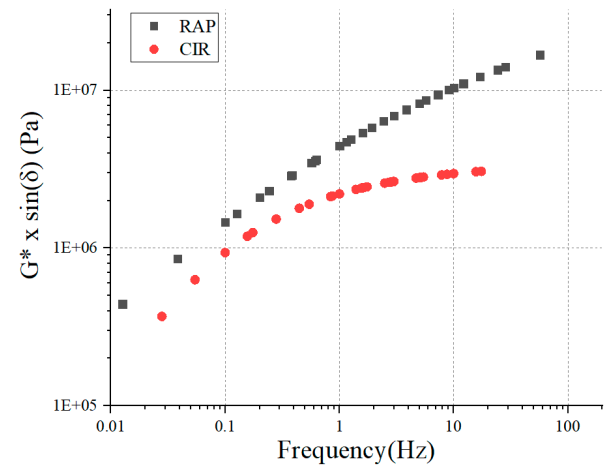

(d) Master curve of fatigue index at $19^{\circ} \mathrm{C}$

Figure 13. DSR test results for RAP and CIR asphalt: (a) The complex modulus of asphalt binder at $58{ }^{\circ} \mathrm{C} ;(\mathbf{b})$ master curve of phase angle at $58{ }^{\circ} \mathrm{C} ;(\mathbf{c})$ master curve of rutting factor at $58{ }^{\circ} \mathrm{C} ;(\mathrm{d})$ master curve of fatigue index at $19{ }^{\circ} \mathrm{C}$.

\section{5. $A B C D$ Results}

In this section, the effect of added emulsion on the low-temperature performance of the asphalt binder was evaluated. According to AASHTO TP 92-11, the cracking temperature was determined based on the strain jump when the fracture stress was recorded. The test results are shown in Figure 14. It should be noted that the addition of emulsion improved the low-temperature cracking resistance of asphalt. It not only increased the fracture stress but also decreased the cracking temperature. For example, the cracking temperature of $\mathrm{CIR}$ with the added emulsion decreased from $-26.45^{\circ} \mathrm{C}$ to $-29.2{ }^{\circ} \mathrm{C}$. The main reason was that the asphalt emulsion made the CIR asphalt binder softer than the RAP asphalt binder. Since CIR asphalt is softer than RAP asphalt, it showed a lower cracking temperature, while RAP asphalt had higher fracture stress. 


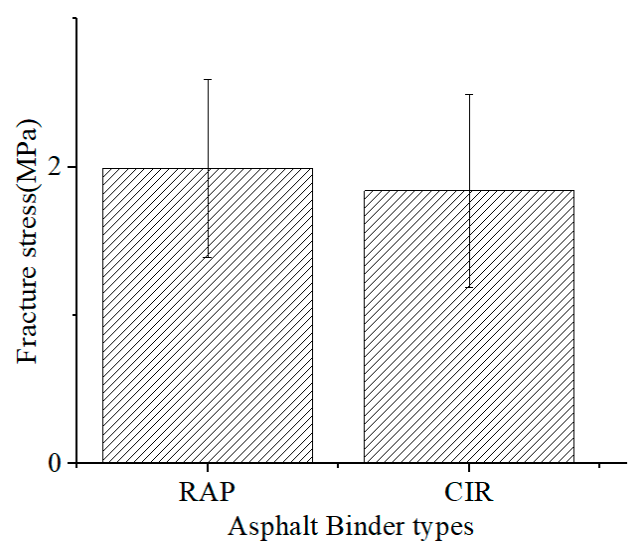

(a) Cracking stress between RAP and CIR asphalt

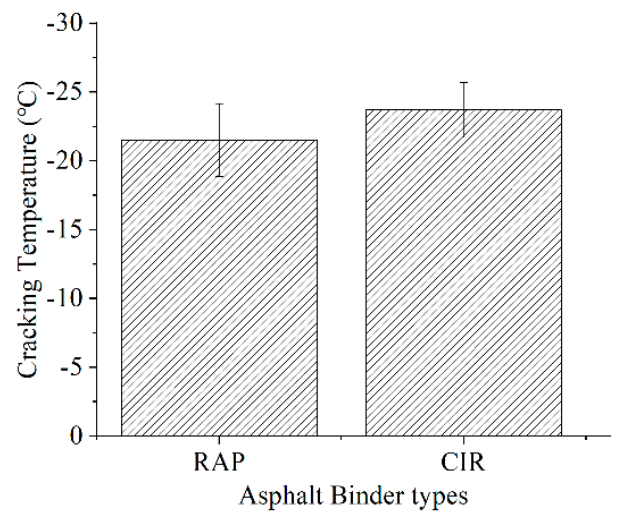

(b) Cracking temperature between RAP and CIR asphalt

Figure 14. Asphalt cracking stress and temperature between RAP and CIR: (a) Cracking stress between RAP and CIR asphalt; (b) Cracking temperature between RAP and CIR asphalt.

\subsection{Pavement Distress Prediction by Pavement M-E Design}

A pavement M-E design was conducted to predict pavement distress [35,36]. The climate data of the place near Dickinson County was used in this study according to the M-E used-guide recommendation. The dynamic modulus from the asphalt mixture and complex shear modulus from the asphalt binder was the input material property that could be used for distress predictions. As described in the method section, the pavement M-E design was used as the pavement distress predictor in this paper because it uses dynamic modulus values and complex shear modulus values to obtain the master curve for asphalt concrete layers. The dynamic modulus values of pre-mist and post-mist CIR asphalt mixture were measured, and the complex shear modulus (extracted from the RAP and CIR) was measured by DSR equipment used in the M-E pavement analysis. The pavement distress prediction results were analyzed based on the dynamic modulus of CIR (pre-mist and post-mist). The complex shear modulus of CIR asphalt was used to do the M-E analysis.

The pavement distress prediction results of the pre-mist and post-mist CIR mixture dynamic modulus are shown in Figure 14. It should be mentioned that the dynamic modulus of pre-mist and post-mist CIR mixture reflected the effect of moisture damage in the CIR pavement layer on the pavement distress predictions, The M-E input parameters of other pavement layers (top, base, and subbase) were based on the reference value from the report [37]. In reality, the moisture damage not only caused deterioration to the leveling layer, but it also affected the top, base, subbase, and subgrade layers. The distress prediction between pre-mist and post-mist CIR mixture in this study only revealed the maximum moisture damage of the CIR layer. Rut depths of the post-mist CIR pavement layer were 0.34 inches higher compared with the pre-mist mixture, which was caused by a reduction in stiffness. It shows an analogous trend with the rutting-factor results based on asphalt mixture dynamic modulus results. Bottom-up fatigue cracking results of the post-mist CIR pavement layer increased by $6 \%$ compared with the pre-mist CIR pavement layer, which implied a similar tendency with the creep compliance and disk-shaped compact tension test results. Furthermore, the international roughness index of the post-mist CIR pavement layer increased by $10 \%$ compared with the pre-mist CIR pavement layer. The results of the average dynamic modulus at pre-mist and post-mist conditions are shown in Table 2. Overall, the moisture damage of the CIR asphalt mixture deteriorated high- and low-temperature performance but it was acceptable when used in a low-volume road. 
Table 2. Average dynamic modulus value pre-mist and post-mist condition.

\begin{tabular}{|c|c|c|c|c|c|c|c|}
\hline \multicolumn{8}{|c|}{ I E* I (MPa) Average Value Pre-Mist Condition } \\
\hline & F (Hz) & 0.1 & 0.5 & 1 & 5 & 10 & 25 \\
\hline \multicolumn{8}{|l|}{$\mathrm{T}\left({ }^{\circ} \mathrm{C}\right)$} \\
\hline-10 & & 7098.3 & 8737.7 & 9418.5 & $10,529.2$ & $11,181.8$ & $12,379.7$ \\
\hline 10 & & 2270.4 & 3125.8 & 3572.8 & 4873.0 & 5404.6 & 6018.4 \\
\hline 21 & & 623.6 & 956.2 & 1216.3 & 2037.7 & 2505.0 & 2979.3 \\
\hline \multirow[t]{2}{*}{37} & & 320.2 & 475.5 & 664.4 & 1047.0 & 1341.7 & 1567.5 \\
\hline & \multicolumn{7}{|c|}{ I E* I (MPa) Average Value Post-Mist Condition } \\
\hline & F (Hz) & 0.1 & 0.5 & 1 & 5 & 10 & 25 \\
\hline \multicolumn{8}{|l|}{$\mathrm{T}\left({ }^{\circ} \mathrm{C}\right)$} \\
\hline-10 & & 5363.1 & 7020.6 & 7789.8 & 9318.7 & 9902.8 & $10,851.1$ \\
\hline 10 & & 1773.2 & 2591.1 & 2851.7 & 3864.8 & 4347.0 & 4898.0 \\
\hline 21 & & 440.6 & 710.4 & 1015.3 & 1556.9 & 1821.7 & 2189.7 \\
\hline 37 & & 198.0 & 296.8 & 429.8 & 669.4 & 764.8 & 999.5 \\
\hline
\end{tabular}

The pavement distress prediction results of RAP and CIR complex shear modulus are shown in Figure 15. It was found that CIR asphalt increased the rut depths of the total pavement and asphalt layer, which was caused by a reduction in stiffness. However, bottomup fatigue cracking results decreased by $1.34 \%$. This showed a similar trend compared with the rutting and fatigue factors from the DSR results. Moreover, the international roughness index (IRI) of CIR asphalt decreased when compared with the RAP asphalt. It should be mentioned that the results just considered the DSR data (RAP and CIR asphalt) on $12.7 \mathrm{~cm}$ CIR layers difference. The input value of other layers was based on the reference value from the report $[37,38]$. The DSR results of RAP and CIR used in this study are shown in Table 3. The pavement distress prediction results were studied by the complex shear modulus (RAP and CIR). The dynamic modulus of the pre-mist CIR asphalt mixture was used to do the M-E analysis. In fact, the dynamic modulus of the RAP asphalt mixture should be used for the M-E design, so the M-E results in Figure 15 did not completely reflect the predicted distress.

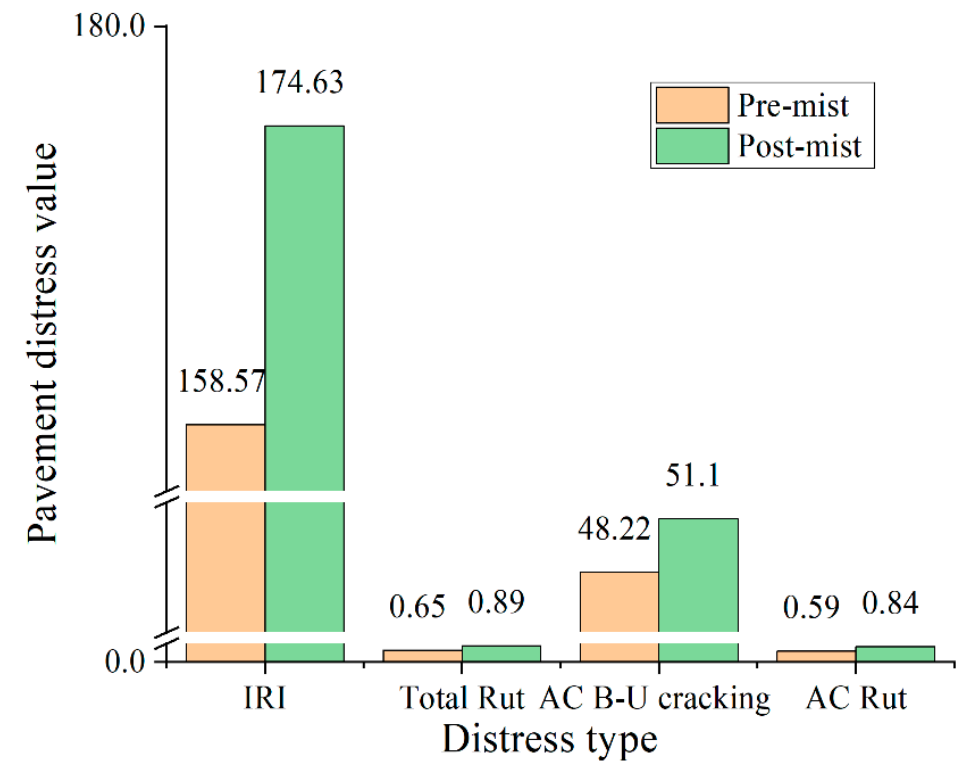

Figure 15. Pavement distress prediction by the dynamic modulus of CIR (pre-mist and post- mist). Note: IRI smoothness (in/mile or $0.016 \mathrm{~m} / \mathrm{km}$ ), Total Rut (in or $0.0254 \mathrm{~m}$ ), AC B-U(bottom-up) cracking (\% lane area), AC Rut (in or $0.0254 \mathrm{~m}$ ), only consider the difference of $12.7 \mathrm{~cm}$ CIR layers. 
Table 3. DSR results of RAP and CIR used in this study.

\begin{tabular}{ccc}
\hline \multicolumn{3}{c}{ Frequency $@ \mathbf{1 0}$ rad/s for RAP } \\
\hline $\mathrm{T}\left({ }^{\circ} \mathrm{C}\right)$ & $\left|\mathrm{G}^{*}\right|(\mathrm{Pa})$ & Phase Angle $^{\circ}$ \\
\hline 13 & $30,628,000$ & 35 \\
25 & $70,84,800$ & 46 \\
34 & $3,888,633$ & 53.6 \\
46 & 621,153 & 62.67 \\
58 & 114,973 & 70.4 \\
\hline & Frequency $@ \mathbf{1 0} \mathbf{~ r a d} / \mathbf{s}$ for CIR \\
\hline $\mathrm{T}\left({ }^{\circ} \mathrm{C}\right)$ & $\left|\mathrm{G}^{*}\right|(\mathrm{Pa})$ & \\
\hline 13 & $14,437,000$ & Phase Angle \\
\hline 25 & $56,78,100$ & 36 \\
34 & $2,281,967$ & 57.3 \\
46 & 354,476 & 66.7 \\
58 & 68,359 & 73.3 \\
\hline
\end{tabular}

The pavement distress prediction results of the RAP and CIR complex shear modulus are shown in Figure 16. It could be founded that CIR asphalt increased the rut depths of the total pavement and asphalt layer, which was caused by a reduction in stiffness. However, bottom-up fatigue cracking results decreased by $1.34 \%$. It showed a similar trend compared with the rutting and fatigue factors from the DSR results. Moreover, the international roughness index (IRI) of CIR asphalt decreased when compared with the RAP asphalt. It should be mentioned that the results just considered the DSR data (RAP and CIR asphalt) on $12.7 \mathrm{~cm}$ CIR layers difference. The input value of other layers was based on the reference value from the report [36]. The pavement distress prediction results were studied by complex shear modulus (RAP and CIR). The dynamic modulus of the pre-mist CIR asphalt mixture was used to do the M-E analysis. In fact, the dynamic modulus of the RAP asphalt mixture should be used for the M-E design, so the M-E results in Figure 16 could not completely reflect the prediction distress.

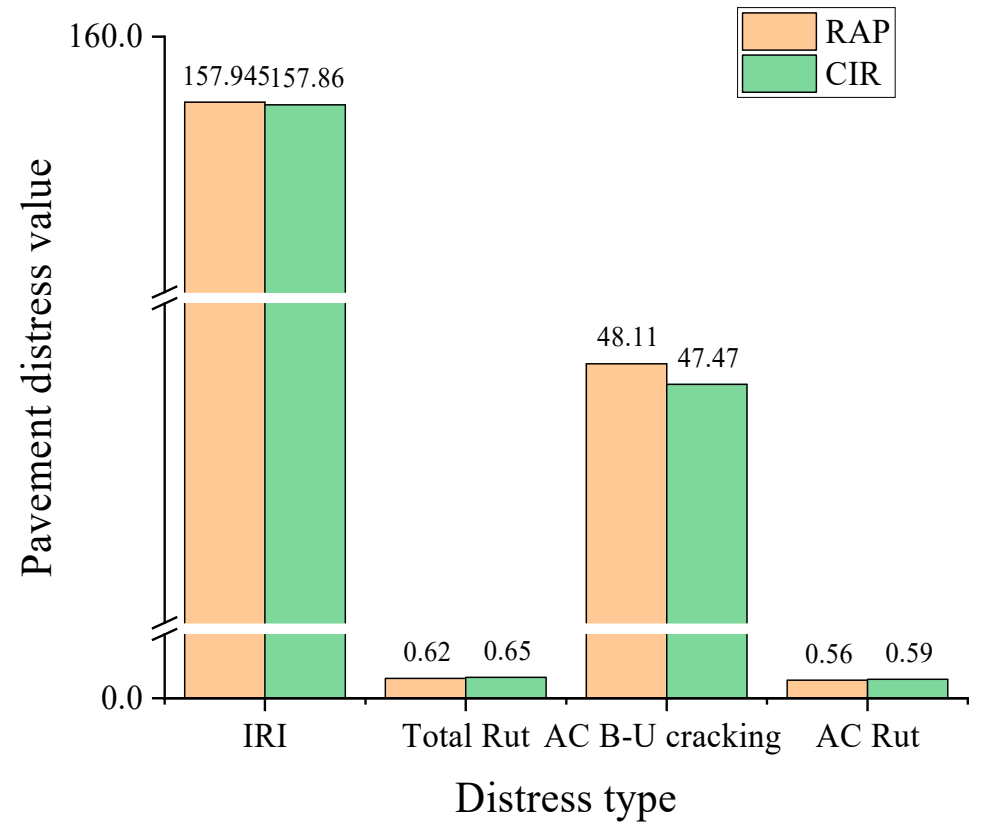

Figure 16. Pavement predicted distresses to complex shear modulus (RAP and CIR). Note: Note: IRI smoothness (in/mile or $0.016 \mathrm{~m} / \mathrm{km}$ ), Total Rut (in or $0.0254 \mathrm{~m}$ ), AC B-U(bottom-up) cracking (\% lane area), AC Rut (in or $0.0254 \mathrm{~m}$ ), only consider the difference of $12.7 \mathrm{~cm}$ CIR layers. 


\section{Field Construction and Pavement Condition Assessment}

A demonstration project was paved by The Dickinson County Road Commission in Dickinson, Michigan, in July 2020. The original roadway condition is shown in Figure 17a,b. It was poor, and the surface layer was milled before the new pavement was placed. The construction procedures in the field are shown in Figure 17c,d. The use of cold in-place recycling restored the old pavement to the desired profile, eliminated existing wheel ruts, restored the crown and cross slope, and eliminate potholes, irregularities, and rough areas. It also eliminated transverse, reflective, and longitudinal cracks. The asphalt emulsion was applied with the milling loose asphalt mixture, and it was placed in the original place as the level layer. After the CIR asphalt pavement layer was compacted, a new top layer was paved over it. The service condition of the road will be estimated in the future.

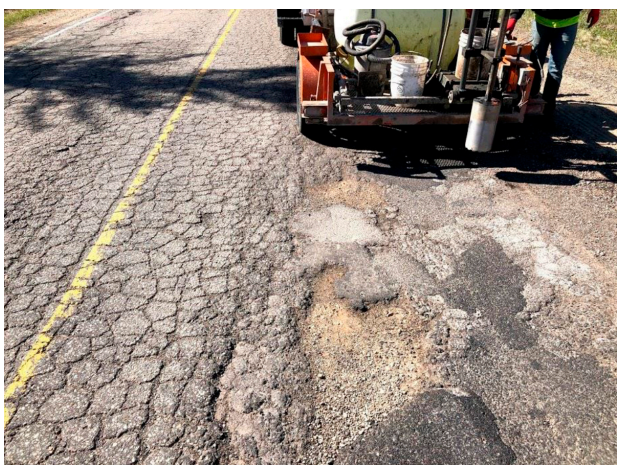

(a) Original road condition at northbound lane station $20+00$

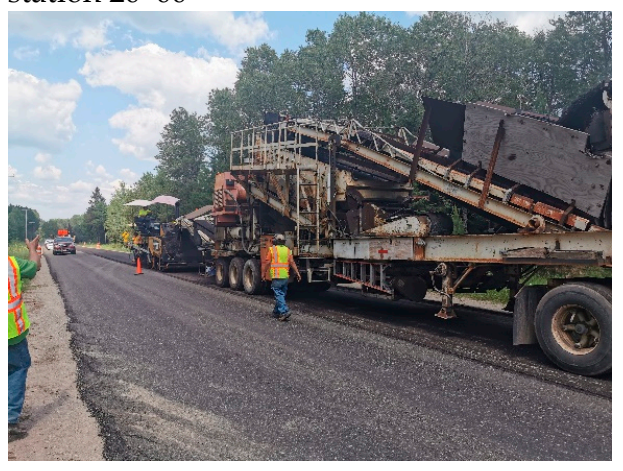

(c) Construction procedure of CIR layer

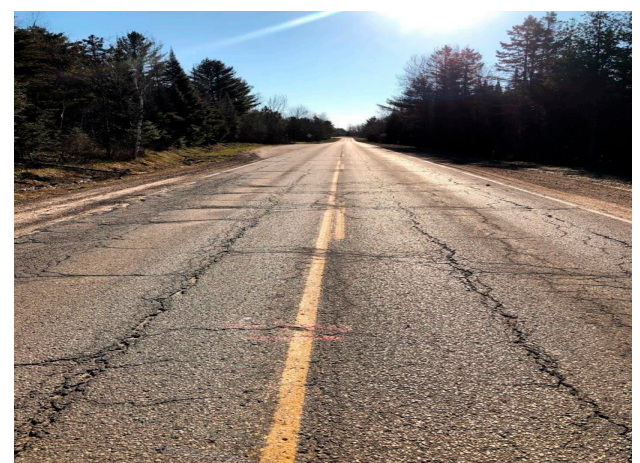

(b) View of the original roadway condition

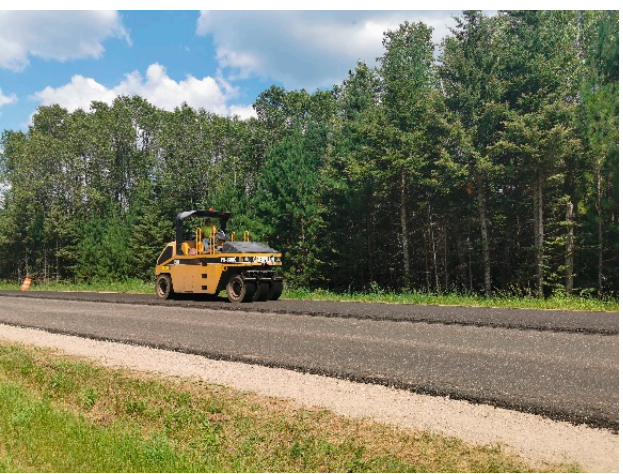

(d) Compaction of the CIR layer

Figure 17. Original roadway condition and construction procedure: (a) Original road condition at northbound lane station 20+00; (b) View of the original existing roadway condition; (c) Construction procedure of CIR layer; (d) Compaction of the CIR layer.

\section{Summary and Conclusions}

This study concentrated on characterizing the CIR asphalt mixture moisture susceptibility performance and extraction of asphalt binder properties to predict the pavement distress and deterioration based on a mechanistic-empirical pavement design. Asphalt mixture moisture susceptibility performance (pre-mist and post-mist) was estimated by the dynamic modulus test, DCT test, and asphalt-binder performance (RAP and CIR asphalt obtained from the standard solvent extraction process). Higher-temperature and mediumtemperature performances were evaluated by DSR equipment and low-temperature properties were estimated by the $\mathrm{ABCD}$. Then the M-E pavement design was conducted to predict the pavement distress. The following conclusions are summarized from this study:

(1) The dynamic modulus test showed that the moisture condition has a significant effect on the CIR asphalt mixture, especially with high temperature and low frequency. The dynamic modulus of the post-mist asphalt mixture decreased $13-43 \%$ at various temperatures and frequencies, but pavement M-E results showed that moisture damage 
of the CIR layer only increased AC Rut and total Rut by 0.34 inches at low traffic volume. It showed that CIR asphalt pavement may still be used for low-volume roads.

(2) Compliance creep, and disk-shaped compact tension test results showed that MIST conditioning decreased the low temperature cracking resistance of the asphalt mixture, and the low-temperature cracking energy of the CIR asphalt mixture decreased $20 \%$ between pre-mist and post-mist condition. The pavement M-E results showed that moisture damage to the CIR layer only increased bottom-up cracking by $2.9 \%$. The lab test results suggest that the performance of CIR materials may have poor performance, but the M-E results showed that it is possible to apply CIR materials on low trafficvolume roads.

(3) The asphalt binder that included emulsion asphalt made the asphalt softer and increased fatigue property and low temperature cracking resistance while decreasing rutting resistance performance.

(4) Pavement M-E analysis based on DSR results of RAP and CIR binder showed that the asphalt binder with emulsion increased the rutting predictions while reducing the IRI, bottom-up fatigue-cracking predictions.

In summary, the implementation of CIR technology in the project improved the lowtemperature cracking and fatigue performance in asphalt pavement. Meanwhile, the moisture damage to the CIR asphalt mixture accelerated the high-temperature rutting and low-temperature cracking performance, but it is possibly acceptable when used for low-volume roads.

Author Contributions: Conceptualization, D.J., D.G., Z.Y.; data curation, D.J., T.C, H.L; methodology, D.J., S.C. and H.L., T.C., L.M; resources, L.M.; supervision, Z.Y.; writing—original draft, D.J.; writingreview \& editing, D.J., D.G., S.C., T.C., H.L., L.M and Z.Y. All authors have read and agreed to the published version of the manuscript.

Funding: This research received no external funding.

Institutional Review Board Statement: Not applicable.

Informed Consent Statement: Not applicable.

Data Availability Statement: The datasets generated during analyzed during the current study are available from the corresponding author on reasonable request.

Acknowledgments: The work is carried out in cooperation with the Dickinson County Road Commission of Michigan. All the test properties are obtained based on the received field loose mixtures.

Conflicts of Interest: The authors declare no conflict of interest.

\section{References}

1. Liu, P.; Xu, H.; Wang, D.; Wang, C.; Schulze, C.; Oeser, M. Comparison of mechanical responses of asphalt mixtures manufactured by different compaction methods. Constr. Build. Mater. 2018, 162, 765-780. [CrossRef]

2. Chen, S.; Ge, D.; Jin, D.; Zhou, X.; Liu, C.; Lv, S.; You, Z. Investigation of hot mixture asphalt with high ground tire rubber content. J. Clean. Prod. 2020, 277, 124037. [CrossRef]

3. Li, X.; Lv, X.; Zhou, Y.; You, Z.; Chen, Y.; Cui, Z.; Diab, A. Homogeneity evaluation of hot in-place recycling asphalt mixture using digital image processing technique. J. Clean. Prod. 2020, 258, 120524. [CrossRef]

4. Wang, C.; Wang, H.; Oeser, M.; Hasan, M.R.M. Investigation on the morphological and mineralogical properties of coarse aggregates under VSI crushing operation. Int. J. Pavement Eng. 2020, 1-14. [CrossRef]

5. Ueckermann, A.; Wang, D.; Oeser, M.; Steinauer, B. Calculation of skid resistance from texture measurements. J. Traffic Transp. Eng. 2015, 2, 3-16. [CrossRef]

6. Epps, J.A. State-of-the-Art Cold Recycling. Transp. Res. Rec. 1980, I, 68-100.

7. BRADBURY, A.; Kazmierowski, T.; Cheng, S.; Raymond, C. Cold in-place recycling in ontario: A case study. In Proceedings of the Thirty-Sixth Annual Conference of Canadian Technical Asphalt Association, Montreal, QC, Canada, April 1991.

8. Scholz, T.V.; Rogge, D.F.; Hicks, R.G.; Allen, D. Evaluation of Mix Properties of Cold In-Place Recycled Mixes. Transp. Res. Rec. $1991,1317,77-89$. 
9. Anderson, D.A.; Luhr, D.R.; Lahr, M. Cold In-Place Recycling of Low-Volume Roads in Susquehanna County Volume I, Technical Report; Vol. 1, no. FHWA-PA-84-020 Final Rpt.; FHWA: Washington, DC, USA, 1985.

10. Carter, A.; Feisthauer, B.; Lacroix, D.; Perraton, D. Comparison of cold In-Place Recycling and Full-Depth Reclamation Materials; No. 10-1325; Transportation Research Board: Washington, DC, USA, 2010.

11. Kim, Y.; Lee, H. "David" Development of Mix Design Procedure for Cold In-Place Recycling with Foamed Asphalt. J. Mater. Civ. Eng. 2006, 18, 116-124. [CrossRef]

12. Cross, S.A. Determination of Ndesign for CIR Mixtures Using the Superpave Gyratory Compactor; University of Kansas Center for Research: Kansas City, KS, USA, 2002.

13. Woods, A.; Kim, Y.; Lee, H. Determining Timing of Overlay on Cold In-Place Recycling Layer: Development of New Tool Based on Moisture Loss Index and in Situ Stiffness. Transp. Res. Rec. J. Transp. Res. Board 2012, 2306, 52-61. [CrossRef]

14. Wu, H.; Huang, B.; Shu, X. Characterizing Fatigue Behavior of Asphalt Mixtures Utilizing Loaded Wheel Tester. J. Mater. Civ. Eng. 2014, 26, 152-159. [CrossRef]

15. Yan, J.; Ni, F.; Tao, Z.; Jia, J. Development of asphalt emulsion cold in-place recycling specifications. In Asphalt Material Characterization, Accelerated Testing, and Highway Management: Selected Papers from the 2009 GeoHunan International Conference; ASCE: Reston, VA, USA, 2009; pp. 49-55.

16. Du, J.-C.; Cross, S.A. Cold in-place recycling pavement rutting prediction model using grey modeling method. Constr. Build. Mater. 2007, 21, 921-927. [CrossRef]

17. Kavussi, A.; Modarres, A. A model for resilient modulus determination of recycled mixes with bitumen emulsion and cement from ITS testing results. Constr. Build. Mater. 2010, 24, 2252-2259. [CrossRef]

18. Thomas, T.; Kadrmas, A.; Huffman, J. Cold In-Place Recycling on US-283 in Kansas. Transp. Res. Rec. J. Transp. Res. Board 2000, 1723, 53-56. [CrossRef]

19. Kim, Y.; Lee, H.D.; Heitzman, M. Dynamic Modulus and Repeated Load Tests of Cold In-Place Recycling Mixtures Using Foamed Asphalt. J. Mater. Civ. Eng. 2009, 21, 279-285. [CrossRef]

20. Graziani, A.; Mignini, C.; Bocci, E.; Bocci, M. Complex Modulus Testing and Rheological Modeling of Cold-Recycled Mixtures. J. Test. Eval. 2020, 48, 120-133. [CrossRef]

21. Cox, B.C.; Howard, I.L. Cold In-Place Recycling Characterization Framework and Design Guidance for Single or Multiple Component binder Systems; A Dissertation in Mississippi State University: Starkville, MS, USA, 2015.

22. AASHTO. Preparation of Cylindrical Performance Test Specimens Using the Superpave Gyratory Compactor (SGC); AASHTO PP 60-09; AASHTO: Washington, DC, USA, 2009.

23. Che, T.; Pan, B.; Sha, D.; Zhang, Y.; You, Z. Relationship between Air Voids and Permeability: Effect on Water Scouring Resistance in HMA. J. Mater. Civ. Eng. 2021, 33, 04021022. [CrossRef]

24. ASTM Standard D7870/7870M. Standard Practice for Moisture Conditioning Compacted Asphalt Mixture Specimens by Using Hydrostatic Pore Pressure; ASTM: West Conshohocken, PA, USA, 2013.

25. ASTM D-7313. Standard Test Method for Determining Fracture Energy of Asphalt-Aggregate Mixtures Using the Disk-Shaped Compact Tension Geometry; American Society for Testing and Materials: West Conshohocken, PA, USA, 2007.

26. Gharaibeh, H.M. Managing the Cost of Power Transmission Projects: Lessons Learned. J. Constr. Eng. Manag. 2013, 139 , 1063-1067. [CrossRef]

27. Si, C.; Zhou, X.; You, Z.; He, Y.; Chen, E.; Zhang, R. Micro-mechanical analysis of high modulus asphalt concrete pavement. Constr. Build. Mater. 2019, 220, 128-141. [CrossRef]

28. American Association of State Highway and Transportation Officials (AASHTO) Standard T 322. Determining the creep compliance and strength of hot-mix asphalt (HMA) using the indirect tensile test device. In Standard Specifications for Transportation Materials and Methods of Sampling and Testing, 25th ed.; AASHTO: Washington, DC, USA, 2011.

29. Park, S.; Schapery, R. Methods of interconversion between linear viscoelastic material functions. Part I-A numerical method based on Prony series. Int. J. Solids Struct. 1999, 36, 1653-1675. [CrossRef]

30. A.S.T.M. Standard. ASTM D8159: Standard Test Method for Automated Extraction of Asphalt Binder from Asphalt Mixtures; ASTM 2019 International: West Conshohocken, PA, USA, 2019.

31. American Association of State and Highway Transportation Officials. AASHTO TP 92-11 Determining the Cracking Temperature of Asphalt Binder using the Asphalt Binder Cracking Device; AASHTO: Washington, DC, USA, 2011.

32. Zofka, A.; Marasteanu, M.; Turos, M. Investigation of Asphalt Mixture Creep Compliance at Low Temperatures. Road Mater. Pavement Des. 2008, 9, 269-285. [CrossRef]

33. Zofka, A.; Marasteanu, M.O.; Turos, M. Determination of Asphalt Mixture Creep Compliance at Low Temperatures by Using Thin Beam Specimens. Transp. Res. Rec. J. Transp. Res. Board 2008, 2057, 134-139. [CrossRef]

34. Ge, D.; You, Z.; Chen, S.; Liu, C.; Gao, J.; Lv, S. The performance of asphalt binder with trichloroethylene: Improving the efficiency of using reclaimed asphalt pavement. J. Clean. Prod. 2019, 232, 205-212. [CrossRef]

35. Dave, E.V. Moisture Susceptibility Testing for Hot Mix Asphalt Pavements in New England; Final Report for New England Transportation Consortium, Project (2018) 15-3; NETC: Durham, NH, USA, 2018.

36. Olidid, C.; Hein, D. Guide for the mechanistic-empirical design of new and rehabilitated pavement structures. In Proceedings of the 2004 Annual Conference and Exhibition of the Transportation Association of Canada-Transportation Innovation-Accelerating the Pace, Quebec City, QC, Canada, September 2004. 
37. You, Z.; Yang, X.; Hiller, J.; Watkins, D.; Dong, J. Improvement of Michigan Climatic Files in Pavement ME Design; Michigan Technological University: Houghton, MI, USA, 2015.

38. Buch, N.; Haider, S.W.; Brown, J.; Chatti, K. Characterization of Truck Traffic in Michigan for the New Mechanistic Empirical Pavement Design Guide; Michigan. Dept. of Transportation, Construction and Technology Division: Lansing, MI, USA, 2009. 